\title{
Investigation of Tribological Behavior of Stainless Steel 304 and Grey Cast Iron Rotating Against EN32 Steel Using Pin on Disc Apparatus
}

\author{
Kapil Chawla ${ }^{1}$, Naveen Saini ${ }^{2}$, Rajeev Dhiman ${ }^{3}$ \\ ${ }^{I}$ (Mechanical Engineering, Lovely Professional University, Jalandhar, India) \\ 2 (Mechanical Engineering, Maharishi Markandeshwar University, Mullana, India) \\ ${ }^{3}$ (Mechanical Engineering, Lovely Professional University, Jalandhar, India)
}

\begin{abstract}
The tribological behavior of stainless steel 304 and grey cast iron was investigated using the pinon-disc standard test with varying sliding speeds and normal loads. A pin-on-disc device with round tool inserts was used to conduct friction wear tests in which the linear wear of the tribo-pairs were continuously recorded versus sliding distance. For the quantitative comparison of the wear resistance of the material was tested by calculating the weight loss. Scanning electron microscopy (SEM) was applied for observations of wear scars and wear products, and the identification of the predominant wear mechanisms which occurred. Some specific frictional behaviors and relevant wear mechanisms observed for both steel 304 and cast iron sliding were highlighted and quantified. It was concluded that with the increase in sliding speed and normal load wear behavior shown by stainless steel 304 was more as it become soften with the increase in the load. But the wear behavior shown by grey cast was low due to the presence of graphite.
\end{abstract}

Keywords: Grey cast iron, Pin on disc, Scanning electron microscopy (SEM), Stainless steel 304, Weighing machine.

\section{INTRODUCTION}

Steels and graphite cast iron are popularly adopted in various engineering applications. Extensive research on oxidative wear of steels has been carried out and the wear behavior and mechanism of steels are clearly understood. However, there has been less study of graphite cast iron and hence the wear behavior and mechanism of graphite cast iron are less clear. So it becomes imperative to analyse the wear characteristics of materials on a case-to-case basis in order to arrive at a more realistic assessment of wear performance. Accordingly, the present study pertains to examine the sliding wear behavior of a grey cast iron at different sliding speeds over a range of applied loads. The wear oxide debris particles have been shown to form nanostructured glaze layers at a higher temperature to enhance wear resistance [1]. Wilson et al. studied the influence of wear oxide debris particles on reducing wear and proposed another important oxidative wear model [2]. Inman et al. also suggested a division of oxidative wear/mild wear into abrasive mild wear and protective mild wear as well as severe wear into standard severe wear and abrasion-assisted-severe-wear [3] Wang et al. further studied oxidative wear of steels in severe testing conditions and pointed out that tribooxides did not always prevent wear, especially when the mild-severe wear transition occurred in oxidative wear [5]. Riahi and Alpas [7] produced the first wear map for grey cast iron, where wear mechanisms were classified into ultra-mild, mild and severe wear. In ultra-mild wear, a compacted oxide film covered contacting surfaces; also mild wear was defined as oxidative wear. Severe wear appeared when oxide layer did not stably form due to delamination of tribo-oxides. They also pointed out that the excellent wear resistance of grey cast iron during dry sliding under low loading conditions was attributed to graphite flakes and formation of a graphite film. Hirasata and Hayashi [6] studied friction and wear of several kinds of cast irons under severe sliding conditions and found that the wear rates were strongly dependent on hardness variation. No tribooxides were noted to exist, only a plastically deformed layer. Prasad [7] studied the effect of micro structural features and test conditions on the wear of cast iron. He pointed out that the governing phenomena of wear in the alloyed cast iron might be due to adhesive wear which generated oxide particulates that further led to abrasive wear. When abrasive wear mode was prominent, the wear took place by ploughing or micro cutting of the hard debris particulates. The main operating materials removal mechanism was spalling associated with substantial micro cracking and with a limited extent of adhesion and abrasion during sliding. Liu [8] studied the influence of surface oxidation on the wear resistance of cast irons and found that oxidation increased wear rate when cast iron was of high strength and hardness. 


\section{WEAR TEST}

Dry sliding wear test for different number of specimen was conducted with the help of pin on disc machine (Model: Wear and Friction monitor TR-20) made by the DUCOM, as shown in the figure 1. The pin was held against the counter surface of sliding disc (EN 32 steel disc) with wear track of diameter $60 \mathrm{~mm}$. The pin was loaded against the disc through a dead weight load system. The wear test of specimen (Steel 304 and Grey cast iron) was treated under the load of $2 \mathrm{~kg}, 3 \mathrm{~kg}, 4 \mathrm{~kg}, 5 \mathrm{~kg}$, and at a speed of 200, 400, 600, $800 \mathrm{rpm}$. The sample used was of $8 \mathrm{~mm}$ dia. and $3.75 \mathrm{~cm}$ in length. The surface of the pin was slide against the emery paper of grit size (80) prior to test in order to ensure effective contact of fresh and flat surface with the steel disc. The samples Steel 304 and grey cast iron) and wear track was cleaned with the help of acetone before experiment. The wear rate was expressed in the terms of weight loss (gm). Morphology of worn out surfaces and substrates was carried out with the help of Scanning electron microscopy (SEM). The chemical composition of steel 304 and grey cast iron which we are using in the current study is shown in Table 1

\section{PARAMETERS AFFESTING SLIDING WEAR}

Friction wear affected by no. of parameters, one of them is lubrication as lubricants can drastically change the friction and wear characteristics of sliding system and also capable of altering the nature of surface interaction between contacting solids. The functions of solid lubricants are same as that of liquids, that is, separation of surfaces and provision of shear path within the interface. Under extreme pressure conditions, the lubricant film can become thin enough to allow direct contact between solids. In boundary lubrication, any separation of surfaces depends on molecules adhered to the surface rather than on a continuous oil film. Second parameter affecting the friction wear is load. Load is directly related to the weld junction as load increases the area of weld junction increase it results in adhesion. As load increases physical failure of metal occurs at the interface due to bulk failure. In general, at low velocities and load friction increases with an increase of speed and it decreases at high speeds and loads. With hard materials such as steel, friction increases with an increase of roughness and load whereas, for soft materials such as rubber, fibre and nylon friction decreases with an increase of load. Third parameter is sliding speed they control the degree of adhesion (metallic intimacy), sub-surface damage, thermo-mechanical effects on the sliding surface. As more sliding speed more frictional heat will generate results in tendency to break the oxide film. With increase in sliding speed and load wear rate increases it may show either linear or non-linear behavior.

\section{WEAR AND FRICTION BEHAVIOR OF STEEL 304 AND GREY CAST IRON}

Figure 2 and 3 shows the weight loss vs. time curves of steel 304 and grey cast iron at various loads. The wear rate of steel 304 at 200rpm increasing very slowly with increasing load. At $400 \mathrm{rpm}$ wear rate increases rapidly from $2 \mathrm{~kg}-5 \mathrm{~kg}$. The wear rate at $600 \mathrm{rpm}$ increases gradually at first increasing load then started to rise rapidly once the load surpassed to $5 \mathrm{~kg}$. The wear rate at $800 \mathrm{rpm}$ was almost double as compared to 400rpm speed. From figure ' $a$ ' it was observed that at 200rpm speed rate of friction in the terms of weight loss increase from 10 minutes to 30 minutes of the operation for handling $2 \mathrm{~kg}, 3 \mathrm{~kg}, 4 \mathrm{~kg}$, $5 \mathrm{~kg}$ weight. For the first 10 minutes the weight loss almost remains constant but as sliding time increases the weight loss increases abruptly. From figure ' $b$ ' it was observed that at 400rpm speed weight loss is almost double as compared to the $200 \mathrm{rpm}$ for handling $2 \mathrm{~kg}, 3 \mathrm{~kg}, 4 \mathrm{~kg}, 5 \mathrm{~kg}$ load. From figure ' $\mathrm{c}$ ' it was observed that at $600 \mathrm{rpm}$ speed weight loss increase becomes constant from 20-30 minutes for handling $2 \mathrm{~kg}-5 \mathrm{~kg}$.

The wear rate of grey cast iron at different speed and loads was shown in the figure 3. It was observed that weight loss of grey cast iron was very small as compared to the steel 304 . With the increase in sliding speed and normal load more adhesion will take place and more breakdown of graphitic structure will take place. More graphite lesser will be the adhesion as graphite acts as a good lubricant this result in the less wear. From figure ' $\mathrm{e}, \mathrm{f}, \mathrm{g}, \mathrm{h}$ ' it was observed at low load that is $2 \mathrm{~kg}$ the weight loss is much high as compared to the higher loads. At higher load (i.e. $5 \mathrm{~kg}$.) the weight loss was less as graphite comes in play.

\section{Sem Morphology Of Worn Surfaces}

SEM morphology of steel 304 and grey cast iron was carried out at 800rpm and at a normal load of $5 \mathrm{~kg}$ as shown in the figure 4-7. Figure 4 showed that at $800 \mathrm{rpm}$ obvious adhesive and a trace of abrasive mark were identified. In addition, some cracks scattered on the worn surface under high load, which can be confirmed by SEM. However, at a load of $5 \mathrm{~kg}$ any trace of smooth tribo-oxide layers and delaminated craters disappeared, instead only a small amount of fine grooves parallel to the sliding direction and cracks appeared. Similarly Morphology of worn surface of grey cast was shown with the help of SEM. From figure 5 and 6 it was observed that with the increase in normal load and sliding speed graphite layers break down and graphite 
comes in to play which acts as a good lubricant. As graphite acts as a good protective layer which leads to less wear as compared to steel 304 . However, the wear rate of the spheroidal graphite cast iron was slightly lower than that of the carbon steel due to graphite lubrication. However, tribo-oxides generated on worn surfaces of the spheroidal graphite cast iron were too little and too thin to avoid metal-metal contact and adhesion, thus the severe wear is dominated.

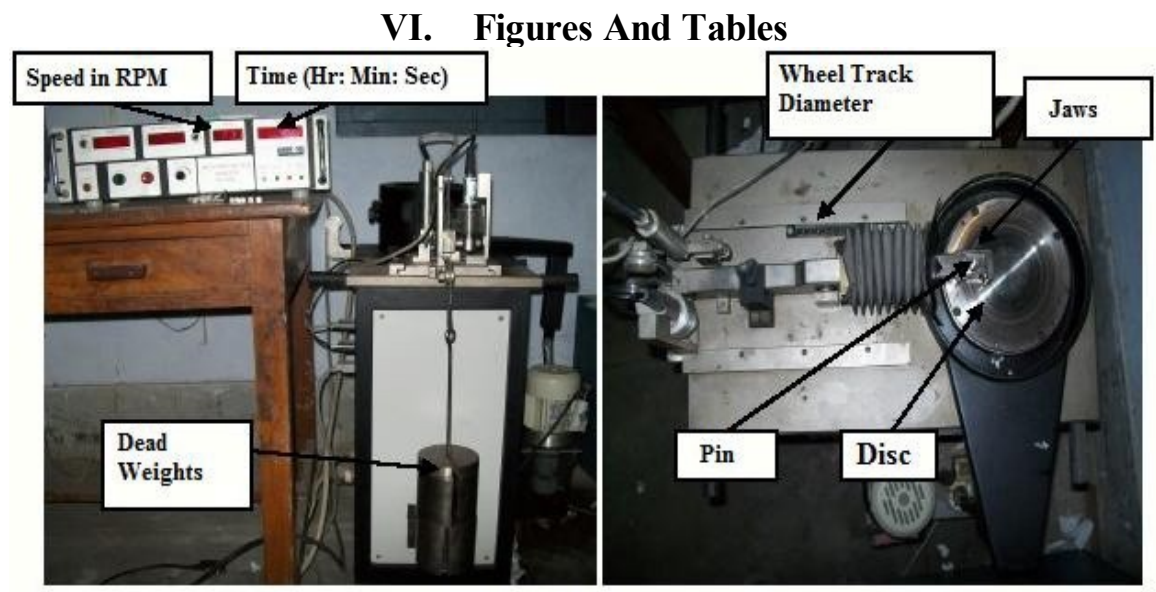

"Fig." 1 Sliding wear apparatus.

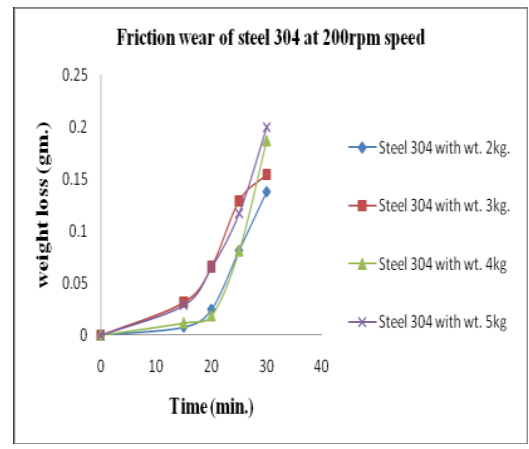

(a)

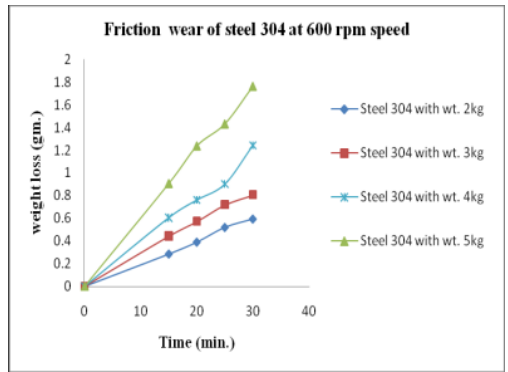

(c)

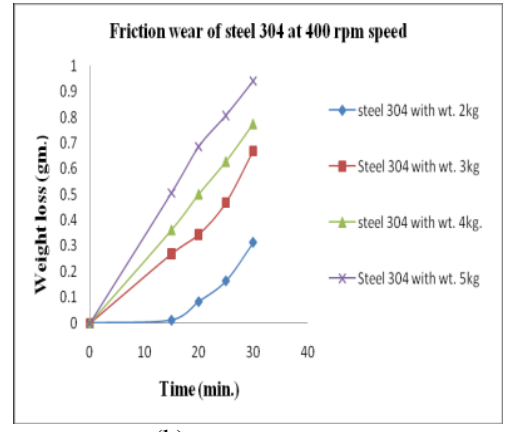

(b)

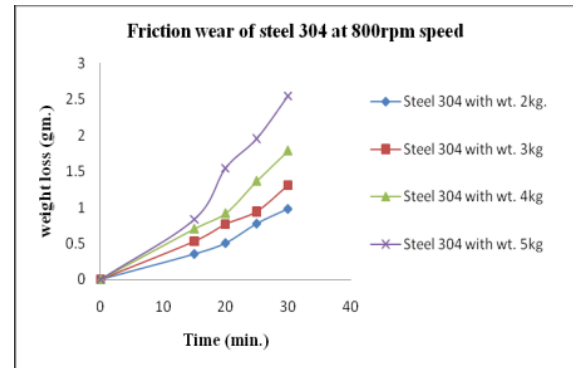

(d)

"Fig." 2(a-d) Sliding wear behavior of steel 304.

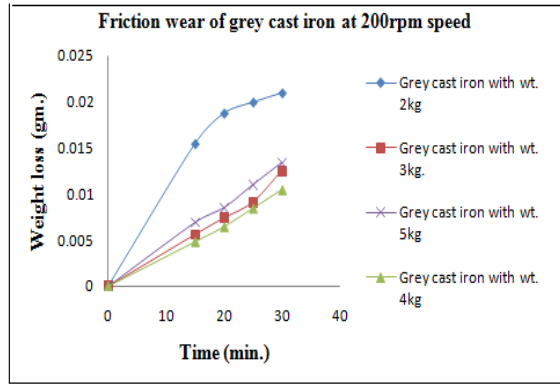

(e)

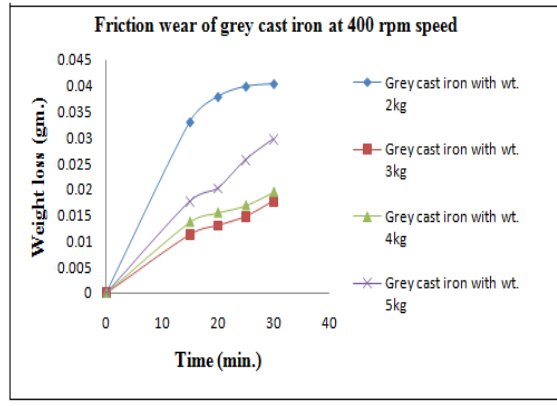

(f) 


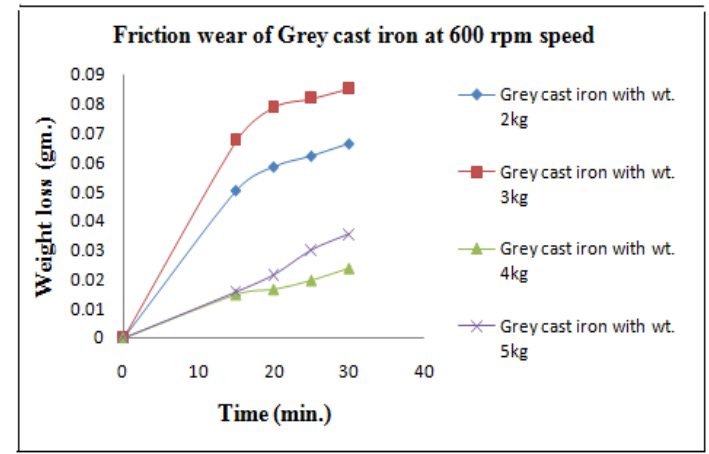

(h)

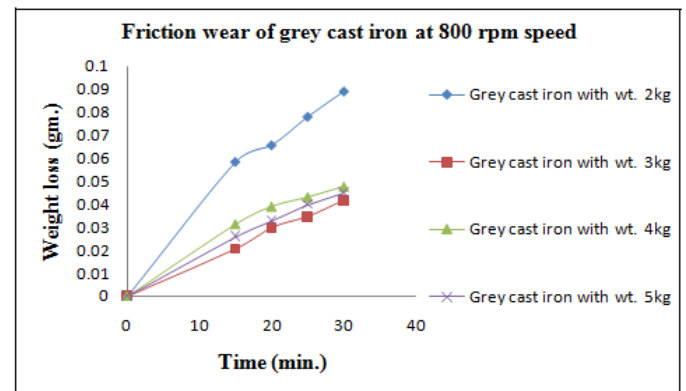

(i)

"Fig." 3(e-h) Sliding wear behavior of grey cast iron.
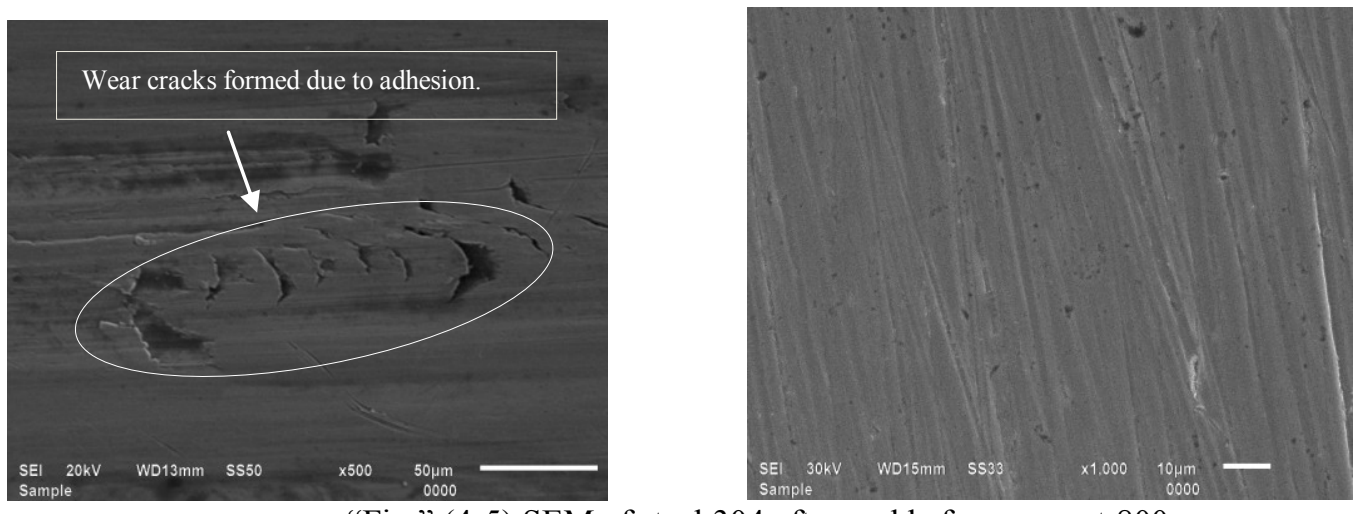

"Fig." (4-5) SEM of steel 304 after and before wear at 800rpm.
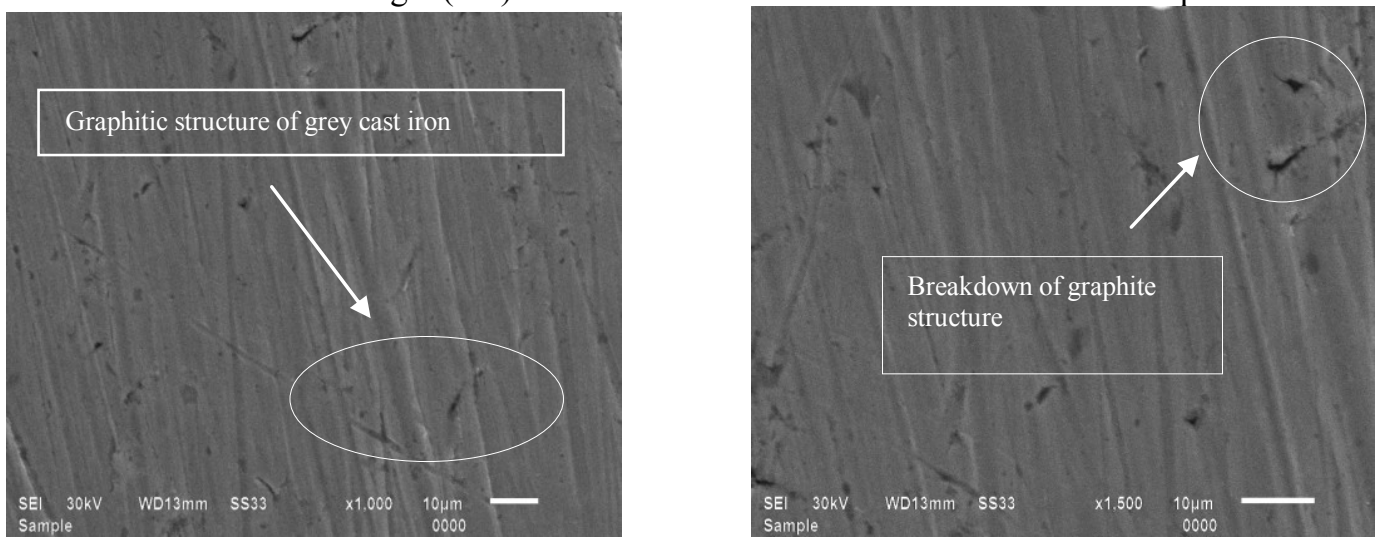

"Fig." (6-7) SEM of grey cast iron before and after wear at 800rpm.

\begin{tabular}{|l|l|l|}
\hline Name of the element (\%) & Percentage average of steel 304 & Percentage average of grey cast iron \\
\hline $\mathrm{Fe} \%$ & 69.4 & 55.7 \\
\hline $\mathrm{C} \%$ & 0.225 & 2.46 \\
\hline $\mathrm{Si} \%$ & 0.439 & 7.00 \\
\hline $\mathrm{Mn} \%$ & 1.73 & 1.47 \\
\hline $\mathrm{P} \%$ & 0.0165 & 0.800 \\
\hline $\mathrm{S} \%$ & 0.0121 & 0.154 \\
\hline $\mathrm{Cr} \%$ & 19 & 0.116 \\
\hline $\mathrm{Ni} \%$ & 0.106 & 0.164 \\
\hline $\mathrm{Al} \%$ & 0.38 & 5.75 \\
\hline $\mathrm{Co} \%$ & 0.0416 & 0.0687 \\
\hline $\mathrm{Cu} \%$ & 0.116 & 0.698 \\
\hline $\mathrm{Mb} \%$ & 0.318 & 4.64 \\
\hline $\mathrm{Ti} \%$ & 0.0044 & 0.181 \\
\hline $\mathrm{V} \%$ & 0.0168 & 0.211 \\
\hline
\end{tabular}

"Table" 1. chemical composition of steel 304 and greya cast iron 


\section{Conclusion}

1. It was observed that higher wear rate and frictional heating led to more severe surface damage. Material adhesion and smearing of the solid lubricant phase were noted to be important wear mechanisms, while abrasion and cracking also contributed to material loss.

2. The wear loss increased with increasing sliding speed and load for both steel 304 and grey cast iron. But the wear rate shown by the stainless steel was more as compared to the grey cast iron. Because grey cast iron has mainly graphitic structure with the increase in sliding speed and load it comes in to play and it acts as a lubricating film.

3. The microstructure of the (cast iron) sample revealed flakes of graphite. With the increase of load decohesion at the graphite/(ferrite) matrix interface was also observed.

\section{References}

[1] I.A. Inman, S. Datta, H.L. Du, J.S. Burnell-Gray, Q. Luo, Microscopy of glazed layers formed during high temperature sliding wear at $750^{\circ} \mathrm{C}$, Wear 254 (2003) 461-467.

[2] J.E. Wilson, F.H. Stott, G.C. Wood, The development of wear protective oxides and their influence on sliding friction, Proc. R. Soc. A 369 (1980) 557-574.

[3] I.A. Inman, P.S. Datta, Development of a simple 'temperature versus sliding speed' wear map for the sliding wear behaviour of dissimilar metallic interfaces II, Wear 265 (2008) 1592-1605.

[4] S.Q. Wang, M.X. Wei, F. Wang, Y.T. Zhao, Transition of elevated temperature wear mechanisms and the oxidative delamination wear in hot-working die steels, Tribol. Int. 43 (2010) 577-584.

[5] A.R. Riahi, A.T. Alpas, Wear map for grey cast iron, Wear 255 (2003) 401-409.

[6] K. Hirasata, K. Hayashi, Friction and wear of several kinds of cast irons under severe sliding conditions, Wear 263 (2007) $790-800$.

[7] B.K. Prasad, Sliding wear response of cast iron as influenced by micro structural features and test condition, Mater. Sci. Eng. 456 A (2007) 373-385.

[8] Y.C. Liu, The influence of surface oxidation on the wear resistance of cast iron, Tribol. Int. 28 (1995) $433-438$.

[9] H.-S. Hong, The role of atmospheres and lubricant in the oxidational wear of metals, Tribol. Int. 35 (2002) $725-729$.

[10] Dwivedi DK, Arjun TS, Thakur P, Vaidya H, Singh K. Sliding wear and friction behaviour of Al-18\%Si-0.5\%Mg alloy.Mater Process Technol 2004;152(3),323-328.

[11] Prasad, B.K.: Sliding wear characteristics of a gray cast iron as influenced by the sliding speed, load and environment. Tribology 2, $128-138$ (2008).

[12] Sahraoui Tahar, Guessasma Sofiane, Ali Jeridane M, Hadji Mohamed. HVOF sprayed WC-Co coatings: microstructure, mechanical properties and friction moment prediction. Mater Design 2010;31:1431-7.

[13] Nascimento MP, Souza RC, Miguel IM, Pigatin WL, Voorwald HJC. Effects of tungsten carbide thermal spray coating by HP/HVOF and hard chromium electroplating on AISI 4340 high strength steel. Surf Coat Technol 2001;138:113-24.

[14] Becker BS, Bolton JD, Eagles AM. Sintering of 316L stainless steels to high density via the addition of chromium-molybdenum dibromide powders. Part 1: sintering performance and mechanical properties. In: Proc instn mech engrs, vol. 214(L); 2000, 13952 . 